\title{
199 MOTIVES FOR COMPETITION AMONG ATHLETE'S OF SELECTED SPORTS AND GAMES AT INTER-VARSITY LEVEL
}

Ashutosh Acharya, Jayashree Acharya Lakshmibai National University of Physical Education, Gwalior, Madhya Pradesh, India

10.1136/bjsm.2010.078725.199

To find out the motives of male intervarsity level players in India ( $\mathrm{N}=160)$ for participating in sports competition in the event of basketball $(\mathrm{N}=40)$, track and field $(\mathrm{N}=40)$, football (40) and gymnastics (40) in the age group of $18-25$ years with a mean and SD of $19.47 \pm 1.42$. Motives for competition questionnaire (Blood, Suinn, 1982) was used to measure the variables. This questionnaire has 19 categories. To examine the hypothesis, descriptive and comparative statistics of analysis of variance was calculated. A significant difference was found in physical fitness and health scores as the obtained ' $\mathrm{f}$ ' value of 5.12 was greater than required value of 4.00 at $3.156 \mathrm{df}$, mean difference was found between basketball players and football players. Significant difference was also found in friendship and personal association scores, as the obtained ' $\mathrm{f}$ ' value of 7.65 was greater than the required value of 4.00 at $3.156 \mathrm{df}$, mean difference was found basketball players and football players as well as between football players and gymnasts. The mean differences were tested at 0.05 level of significance. No significant difference was found in other 17 categories of motives (social approval, competition, self mastery, life style, fear of failure, success and achievement, tangible pay offs, recognition, intimidation/control, heterosexuality, competing conditions/ crowd, independence/individuality, family, emotional release, status, self-direction/awareness and understanding reasons) for competition among the selected group players. 